\title{
Fruit juice consumption in the National Diet and Nutrition Survey (NDNS 2008-2010): associations with diet quality and indices of obesity and health
}

\author{
Sigrid Gibson \\ Sig-Nurture Ltd., 11 Woodway, Guildford Surrey, GU1 2TF, UK
}

Fruit juice (FJ) can provide significant quantities of essential micronutrients, such as potassium, magnesium, folate, vitamin A and vitamin $\mathrm{C}$ as well as polyphenolic compounds. FJ consumption has been associated with superior dietary quality ${ }^{(1)}$ and with cardiovascular benefits including improved endothelial function ${ }^{(2)}$ and reduced risk of stroke ${ }^{(3)}$.

This study analysed 2 years of data (2008-2010) from the National Diet and Nutrition Survey (NDNS) using files obtained from the UK Data Archive ${ }^{(4)}$. The purpose was to explore associations between fruit juice consumption and dietary quality (macro- and micronutrient intakes), socio-demographic and lifestyle factors and health indices, including anthropometric measures. NDNS is a cross-sectional survey on a rolling basis, 4-day food diaries were available for 2126 respondents ( $n 1095$ children aged 1 to $18 \mathrm{y}$; $n 1031$ adults aged $19 \mathrm{yrs}$ upwards). Data were weighted to account for sampling and non-response bias. Consumers of (100\%) FJ were defined as those who recorded drinking any FJ during the survey. Regression was used to adjust for effects of age and sex on anthropometric indices.

Mean FJ consumption over the total population was $70 \mathrm{~g} / \mathrm{d}$, (146 g/d among consumers). FJ consumption was associated with higher dietary quality ( $\%$ of RNI) and lower risk of inadequacy ( $\%<\mathrm{LRNI})$ for several micronutrients. FJ consumers ate more fruit and vegetables than non-consumers and were more likely to achieve the 5-a-day target. Children who consumed FJ also consumed fewer soft drinks (both sugar-sweetened and low calorie) and savoury snacks but this was not observed for adults. FJ consumers had lower BMI (adjusted mean difference $-1.2 \mathrm{~kg} / \mathrm{m}^{2}$ for adults $P=0.001 ;-0.6 \mathrm{~kg} / \mathrm{m}^{2}$ for children, $P=0.003$ ). Adult consumers also had lower waist circumference $(-2.9 \mathrm{~cm}, P=0.002)$ than non-consumers. They were also more likely to have higher education and higher income, to be non-smokers and to rate their health as very good.

\begin{tabular}{|c|c|c|c|c|c|c|c|}
\hline & & \multicolumn{3}{|c|}{ Child } & \multicolumn{3}{|c|}{ Adult } \\
\hline & & non-consumer & consumer & $P$ value & non-consumer & consumer & $P$ value \\
\hline \multirow{3}{*}{\multicolumn{2}{|c|}{$\begin{array}{lr} & \text { Valid N } \\
\text { Fruit juice } & \text { Mean g/d } \\
\text { Fruit and vegetables (excl. juice) } & \end{array}$}} & 500 & 595 & & 608 & 423 & \\
\hline & & 0 & 155 & & 0 & 133 & \\
\hline & & 168 & 204 & $<0.0001$ & 263 & 334 & $<0.0001$ \\
\hline \multicolumn{2}{|c|}{ Soft drinks (non-diet) mean $\mathrm{g} / \mathrm{d}$} & 213 & 176 & 0.013 & 112 & 136 & ns \\
\hline \multicolumn{2}{|c|}{ Soft drinks (diet) mean $\mathrm{g} / \mathrm{d}$} & 215 & 160 & 0.003 & 95 & 74 & ns \\
\hline Magnesium & Mean as \% RNI & 99 & 114 & $<0.0001$ & 87 & 95 & $<0.0001$ \\
\hline Potassium & Mean as $\%$ RNI & 111 & 130 & $<0.0001$ & 78 & 87 & $<0.0001$ \\
\hline Folate & Mean as \% RNI & 131 & 156 & $<0.0001$ & 126 & 144 & $<0.0001$ \\
\hline Vitamin A & $\%<\mathrm{LRNI}$ & $10.7 \%$ & $7.2 \%$ & 0.038 & $8.2 \%$ & $3.4 \%$ & 0.001 \\
\hline Vitamin C & $\%<$ LRNI & $1.4 \%$ & $0.0 \%$ & 0.004 & $1.0 \%$ & $0.0 \%$ & 0.04 \\
\hline
\end{tabular}

FJ consumption contributes to better dietary quality, did not displace whole fruit and vegetables, and is a marker for healthier diet and lifestyle. Consuming FJ was associated with leanness rather than obesity, although no causal inferences can be drawn. Exploration of dietary patterns and confirmation of the observed associations using biochemical and haematological status measures is desirable. From current evidence it would seem that moderate consumption of fruit juice should be positively encouraged on nutritional grounds, especially as less than half the population currently consume fruit juice regularly.

This project was funded by PepsiCo and followed ILSI guidelines for conflict of interest and scientific integrity.

1. O'Neil CE, Nicklas TA, Rampersaud GC, et al. (2011) Nutr Res 31, 673-682.

2. Buscemi S, Rosafio G, Arcoleo G et al. (2012) Am J Clin Nutr 95, 1089-1095.

3. Cassidy A, Rimm EB, O'Reilly EJ, et al. (2012) Stroke 43, 946-951.

4. Link to UK Data Archive. http://www.esds.ac.uk/findingData/snDescription.asp?sn=6533. 